\title{
A novel and large area suitable water-based ink for the deposition of cobalt sulfide films for solar energy conversion with iodine-free electrolytes
}

\author{
Mirko Congiu $^{\mathrm{a}, *}$, Alessandro Lanuti ${ }^{\mathrm{b}, 1}$, Aldo di Carlo ${ }^{\mathrm{b}, 1}$, Carlos F.O. Graeff ${ }^{\mathrm{a}, \mathrm{c}}$ \\ ${ }^{a}$ UNESP-Univ. Estadual Paulista, POSMAT-Programa de Pós-Graduação em Ciência e Tecnologia de Materiais, Av. Eng. Luiz Edmundo Carrijo \\ Coube 14-01, Bauru, SP 17033-360, Brazil \\ ${ }^{\mathrm{b}}$ CHOSE - Centre for Hybrid and Organic Solar Energy, Department of Electronic Engineering, University of Rome Tor Vergata, Via del Politecnico \\ 1, 00133 Rome, Italy \\ ${ }^{\mathrm{c}}$ Department of Physics, Faculty of Sciences-UNESP, Bauru, SP, Brazil
}

Received 6 April 2015; received in revised form 23 June 2015; accepted 26 August 2015

Available online 10 September 2015

Communicated by: Associate Editor H. Upadhyaya

\begin{abstract}
A novel, cheap, reliable water based precursor ink has been used for the large scale production of amorphous cobalt sulfide (CoS) on fluorine doped tin oxide (FTO). The method uses a metal-organic complex of Co(II) and thioglycolic acid (TGA), it is cheap and easy to prepare. The electrodes prepared using our method have been applied in the oxidation/reduction using different redox couples dissolved in liquid electrolytes containing: $\mathrm{I}^{-} / \mathrm{I}_{3}^{-}$; ferrocene/ferrocenium; bipyridine $\left[\mathrm{Co}(\mathrm{bpy})_{3}\right]^{2+/ 3+}$ complexes and sodium polysulfide. The composition, morphology and the efficiency of the CoS electrodes have been investigated. The CoS films show a good adherence to the substrate, good transparency and an excellent electrocatalytic efficiency with all of the different redox electrolytes. The electrodes have been used in DSSC devices using the organic dye D5 with efficiencies up to $6.8 \%$.
\end{abstract}

(c) 2015 Elsevier Ltd. All rights reserved.

Keywords: Iodine-free; Electrolytes; DSSC; Cobalt sulfide

\section{Introduction}

Dye sensitized solar cell (DSSC) (O'regan and Grätzel, 1991 ) is a very interesting technology due the facility of production, good efficiencies up to $13 \%$ (Mathew et al., 2014) and low costs. A typical DSSC consists of a dye, responsible for the light absorption, anchored to a wide band-gap semiconductor, such as $\mathrm{TiO}_{2}$. The photocurrent is generated by the injection of electrons into the conduction band of the

\footnotetext{
* Corresponding author.

E-mail address: mirko.congiu@fc.unesp.br (M. Congiu).

${ }^{1}$ Fax: +3906 96038029 .
}

n-type $\mathrm{TiO}_{2}$. After the charge injection, the dye is regenerated by a redox couple, dissolved in a liquid electrolyte. The redox couple is finally regenerated on the surface of the counter electrode, ensuring the continuous functioning of the device. The $\mathrm{I}^{-} / \mathrm{I}_{3}^{-}$redox couple is generally used, in DSSCs electrolytes, despite the problems related to the long-term stability (Lee et al., 2010; Yanagida et al., 2009) and the partial absorption of visible light (Hamann, 2012). Iodine-free liquid electrolytes based on cobalt (II)/(III) organic complexes (shuttles) have been applied with efficiencies up to $12.3 \%$, in DSSC sensitized with a porphyrin organic dye (Yella et al., 2011). Another interesting 
redox couple is the ferrocene/ferrocenium $\left(\mathrm{Fc} / \mathrm{Fc}^{+}\right)$proposed, for DSSC sensitized with organic and natural dyes (Daeneke et al., 2011; Sönmezoğlu et al., 2012). Other advantages of both $\mathrm{Fc} / \mathrm{Fc}^{+}$and $\left[\mathrm{Co}(\mathrm{bpy})_{3}\right]^{2+/ 3+}$ shuttles are the low molar extinction coefficients in the visible region and the mono-electronic redox reaction, different from than of the $\mathrm{I}^{-} / \mathrm{I}_{3}^{-}$that involves two electrons and the formation of highly reactive radical species (Boschloo and Hagfeldt, 2009). The counter electrode (CE) is a fundamental part of a dye solar cell. In a typical DSSC the CE consists of a thin transparent layer of platinum nanoparticles deposited on the FTO by sputtering, electrodeposition or screenprinting (SP) (Khelashvili et al., 2006; Lan et al., 2010). The technique for $\mathrm{Pt}$ counter electrodes preparation is screen printing of a paste based on hexachloroplatinic acid (HCPT), a chemical precursor of Pt. This relatively simple process has led to its widespread use. In fact, HCPT is soluble in ethanol and water, solvents that are commonly used for the preparation of SP pastes. The same precursor can be used in other deposition techniques such as spin coating (Lan et al., 2010) and electrodeposition (Fu et al., 2012). However platinum is a scarce and expensive element and thus its application increases the costs of DSSC. Several different materials have been proposed to replace Pt such as multi-walled carbon nanotubes (AbdulAlmohsin et al., 2012; Ahn et al., 2014; Anwar et al., 2013), graphene (Wang and $\mathrm{Hu}, 2012$ ), carbon-based nano materials (Ahmad et al., 2014) and transition metal sulfides such as $\mathrm{Ni}_{2} \mathrm{~S}_{3}$ and $\mathrm{CoS}$ (Lin et al., 2011; Yang et al., 2014). Cobalt sulfide in particularly, has been demonstrated in numerous studies to be more efficient than platinum in the catalytic reduction of triiodide $\left(\mathrm{I}_{3}^{-}\right)$to iodine $\left(\mathrm{I}^{-}\right)$in DSSC electrolytes (Congiu et al., 2015; Wang et al., 2009). Among those counter electrodes with high catalytic efficiency, $\mathrm{CoS}$ has shown a reasonably good chemical stability with the $\mathrm{I}^{-} / \mathrm{I}^{3-}$ redox couple. In functioning DSSCs devices a 30 day study was conducted by (Lin et al., 2011) showing good stability in all cell parameters. In our previous research on $\mathrm{CoS}$ counter electrodes we have investigated the effect of electrochemical stress on the electrocatalytic activity of dummy cells (Congiu et al., 2015). Another advantage of $\mathrm{CoS}$ is that it can also be used in quantumdot sensitized solar cells (QDSSC) (Faber et al., 2013). It is important to remember that platinum counter electrodes are unsuitable for QDSSCs uses due the surface poisoning caused by sulfur polysulfide electrolytes normally used in these type of solar cells (Ke et al., 2014; Meng et al., 2014). Despite the great advantages and reduced costs, cobalt sulfide counter electrode is not as commonly used as $\mathrm{Pt}$, and remains excluded from industrial production. In fact there is still no commercial product based on this material. Among the reasons why, are the preparation methods proposed so far in the literature for CoS CE. One of the most common technique for the deposition of $\mathrm{CoS}$ is electrodeposition (ED). This technique produces excellent CEs, however it requires the use of highly toxic precursors such as thiourea (Lin et al., 2011; Wang et al., 2009; Yang et al., 2014). Recently chemical vapor deposition (CVD) has been used to prepare efficient CoS CEs (Mgabi et al., 2014). However both CVD and ED are not ideal for large area electrodes nor for large scale production. It is important to remember that modern industrial production of DSSC is based on SP and other printing techniques. An interesting review work on solar cells counter electrodes materials, was recently published by Yun et al. (2014). In this review work, the authors, highlighted the importance of printing and in-situ growth process as the requirements for future research in the field of Pt-free counter electrodes. Previously, we proposed a new single precursor route for the deposition of efficient and cheap CoS CEs (Congiu et al., 2015) using an ink based on cobalt diethyldithiocarbamate $\left(\mathrm{CoDTC}_{2}\right)$ as chemical precursor. However this ink could only be prepared using organic solvents, which are not ideal for large-scale production. In this paper we propose a new single precursor-based method suitable for the large area and large scale production of efficient CoS CEs for DSSC and QDSSC. The method is based on a water soluble chemical precursor that is cheap and easy to prepare. We have tested these CoS CEs with different redox couples, such as $\mathrm{Fc} / \mathrm{Fc}^{+}$(Daeneke et al., 2011; Sönmezoğlu et al., 2012) and $\left[\mathrm{Co}(\mathrm{bpy})_{3}\right]^{2+/ 3+}$ electrolytes as well as a polysulfide electrolyte suitable for QDSSC.

\section{Materials and methods}

Sulfur (S); sodium sulfide nonahydrate; cobalt chloride hexahydrate $\left(\mathrm{CoCl}_{2} \cdot 6 \mathrm{H}_{2} \mathrm{O}\right)$; thioglycolic acid (TGA); ferrocene $\left(\mathrm{Fe}\left(\mathrm{C}_{5} \mathrm{H}_{5}\right)_{2}\right) ; \mathrm{NOBF}_{4}$, ferrocenium tetrafluoroborate $\left(\mathrm{Fe}\left(\mathrm{C}_{5} \mathrm{H}_{5}\right)_{2} \mathrm{BF}_{4}\right) ;$ propylene carbonate (PEC); chenodeoxycolic acid (CHENO); absolute ethanol (EtOH); acetonitrile (ACN) and fluorine doped tin oxide coated glass slides (FTO $\sim 7 \Omega / \square$ ) were purchased from SigmaAldrich. Titanium dioxide $\left(\mathrm{TiO}_{2} \sim 20 \mathrm{~nm}\right.$ nanoparticles) transparent screen-printing paste; Platisol $\mathrm{T} \backslash \mathrm{SP}$ paste and high stability $\mathrm{I}^{-} / \mathrm{I}_{3}^{-}$electrolyte BV12 (HSE) were purchased from Dyers, Italy and Solaronix. The organic dye 3-(5-(4(diphenylamino)styryl)thiophen-2-yl)-2-cyanoacrylic acid (D5) was purchased from Dyenamo, Sweden. Thermogravimetry (TG) and differential scanning calorimetry (DSC) were performed on a Netzsch Thermische Analyse-STA 409 equipment, under nitrogen atmosphere. X-ray diffraction patterns (XRD) were collected on powder samples with a DMAX Ultima (Rigaku International Corporation, Tokyo, Japan), operating at $40 \mathrm{kV}$ and $2 \mathrm{~mA}$. Scans were performed from $5^{\circ}$ to $80^{\circ}$ with a step size of $0.02^{\circ}$ with a scan speed of $2 \% \mathrm{~min}$. Scanning electron microscopy and energy dispersive X-ray spectroscopy (EDS) were performed using a Zeiss EVO LS15SEM microscope. Electrochemical impedance spectroscopy (EIS) spectra were collected on bisymmetric devices at $0 \mathrm{~V}$ and on complete DSSC devices at $V_{\text {oc }}$ applying a sinusoidal modulation with a $10 \mathrm{mV}$ amplitude with a 
variable frequency from $100 \mathrm{mHz}$ to $100 \mathrm{kHz}$. The EIS characterization was performed on an Autolab PGStat 300 , equipped with a FRA2 impedance module. Cyclic voltammetry was carried out on the same equipment varying the applied potential between -1.0 and $1.0 \mathrm{~V}$ with different scan rates. Cyclic voltammetry was performed on dummy cells with $\mathrm{I}^{-} / \mathrm{I}_{3}^{-}, \mathrm{Co}(\mathrm{II}) / \mathrm{Co}$ (III), polysulfide and ferrocene-based electrolytes. The characterization of complete DSSCs devices have been performed through JV curves under simulated sun light, using a Newport full spectrum solar simulator with a $150 \mathrm{~W}$ lamp and AM1.5. All of the JV measurements have been performed at 1 sun light intensity.

\subsection{Preparation of the chemical precursors inks}

The thioglycolic acid (TGA) complex of $\mathrm{Co}$ (II) has been used as water soluble chemical precursor. The precursors can be easily prepared through the following procedure. Briefly, $1 \mathrm{~mL}$ of TGA was dissolved in $10 \mathrm{~mL}$ of Milli-Q water then the $\mathrm{pH}$ of the solution was increased to slightly alkaline (7.5-8.0) by dropping a concentrated (7 M) ammonium hydroxide solution. In another Becker, the stoichiometric quantity (1:1) of cobalt chloride was dissolved in $10 \mathrm{~mL}$ of Milli-Q water. The two solution are mixed and a dark brown solution is immediately obtained. The TGA-metal complex was precipitated by the addition of absolute ethanol until the starting of the flocculation. The dark suspension was let to precipitate for 20-30 min without stirring. After this time the suspension was filtered on a Büchner funnel under reduced pressure. The precipitate was washed several times with absolute ethanol and was let to dry at ambient temperature. The precursor was dissolved in deionized water in order to prepare the ink. The concentration of the precursor was $1 \mathrm{mg} / \mathrm{mL}$.

\subsection{Deposition of thin films}

The precursor ink was dropped on a square $(2 \times 2 \mathrm{~cm})$ glass or FTO substrates. The ink was uniformly distributed on the whole surface of the substrate. The as deposited ink was dried at $50{ }^{\circ} \mathrm{C}$ precursor over a laboratory hotplate. In this way a uniform film was obtained. The substrates were transferred into a quartz tube. The chemical precursor $\mathrm{CoSCH}_{2} \mathrm{CO}_{2}$ was thermally converted to cobalt sulfide at $300{ }^{\circ} \mathrm{C}$ during $30 \mathrm{~min}$. In order to minimize the contact with atmospheric oxygen during the thermal treatment, the quartz tube was connected to a nitrogen line $\left(\mathrm{O}_{2}<5 \mathrm{ppm}\right)$. After the temperature $\operatorname{ramp}\left(10^{\circ} \mathrm{C} / \mathrm{min}\right)$, the substrates were let to cool at ambient temperature and then was removed from the tube, washed with water and isopropyl alcohol and dried at ambient temperature. The films were stored without special cares at ambient conditions until the use. Pt counter electrodes have been prepared on FTO by drop casting a $50 \mathrm{mM}$ solution of hexachloroplatinic acid in isopropyl alcohol. The as deposited electrodes were heated to $450{ }^{\circ} \mathrm{C}$ for $15 \mathrm{~min}$.

\subsection{Preparation of the electrolytes}

The iodine/iodide based DSSC electrolyte was purchased from Dyers, Italy. The polysulfide electrolyte (PSE) was prepared dissolving $0.1 \mathrm{M}$ of $\mathrm{S}$ in a $0.5 \mathrm{M}$ $\mathrm{Na}_{2} \mathrm{~S}$ (Jun et al., 2013). The preparation of the ferrocene based electrolyte (FCE) was carried out in a glove box, under nitrogen atmosphere due the instability of the ferrocenium ion in contact with oxygen (Zotti et al., 1998). The FCE was prepared in acetonitrile and propylene carbonate 30:70 v:v, with $0.05 \mathrm{M}$ ferrocenium $\left(\mathrm{Fc}^{+}\right)$and $0.1 \mathrm{M}$ ferrocene $(\mathrm{Fc})$ as suggested by Daeneke et al. (2011).

The cobalt based liquid electrolyte (CoLE) has been prepared as follows: 1 equiv of $\mathrm{CoCl}_{2}-6 \mathrm{H}_{2} \mathrm{O}$ and 3.3 equiv of the polypyridine ligand were dissolved in a minimal amount of methanol, and the solution was stirred at reflux for $2 \mathrm{~h}$. An excess of ammonium hexafluorophosphate was then added to the solution to precipitate the compound that was filtered, washed with methanol and ethanol, dried under vacuum, and used without further purification. The oxidation of the $\mathrm{Co}$ (II) complex was performed by adding a slight excess of $\mathrm{NOBF}_{4}$ as suggested by Feldt et al. (2010). The resulted powder were finally dissolved in acetonitrile and MPN to obtain a solvent ratio of 30:70.

\subsection{Fabrication of DSSC and dummy cells}

The photoanodes (PAs) were fabricated by screenprinting the nanocrystalline $\mathrm{TiO}_{2}$ paste on a fresh cleaned FTO substrate, using a square layout $\left(0.25 \mathrm{~cm}^{2}\right)$. The as deposited PAs were transferred into an alumina furnace and annealed at $480{ }^{\circ} \mathrm{C}$ for $30 \mathrm{~min}$. The annealed PAs were let to cool slowly to almost $80^{\circ} \mathrm{C}$, then were dipped into a solution of $0.5 \mathrm{mM}$ D5 with $16 \mathrm{mM}$ of CHENO in acetonitrile:t-butanol (1:1 v:v) for $17 \mathrm{~h}$. The coloration with N719 was performed in a $0.3 \mathrm{mM}$ solution of the dye in absolute ethanol during $16 \mathrm{~h}$ at ambient temperature. After coloration, the PAs were rinsed throughly with absolute ethanol and dried before cell mounting. The counter electrode was sealed with the PA using a hot-melt Bynel ${ }^{\circledR}$ mask with a little hole on the bottom side. The iodine based electrolyte was injected in the DSSC by vacuum back filling and the hole was finally sealed with a melted piece of Bynel $^{\circledR}$. After the final sealing, the cells were let to stabilize in the dark for $24 \mathrm{~h}$ before measurements. In the case of the dummy cell, two identical counter electrodes have been sealed using the same configuration of the complete DSSC. Ferrocene, polysulfide and cobalt based electrolytes have been used in order to evaluate the efficiency of the electrode with different redox couples.

\section{Results}

The thermal degradation of the water soluble CoS chemical precursor, prepared according to the procedure described in the previous section, was studied through TG and DSC. As shown in Fig. 1, there is a first mass loss 


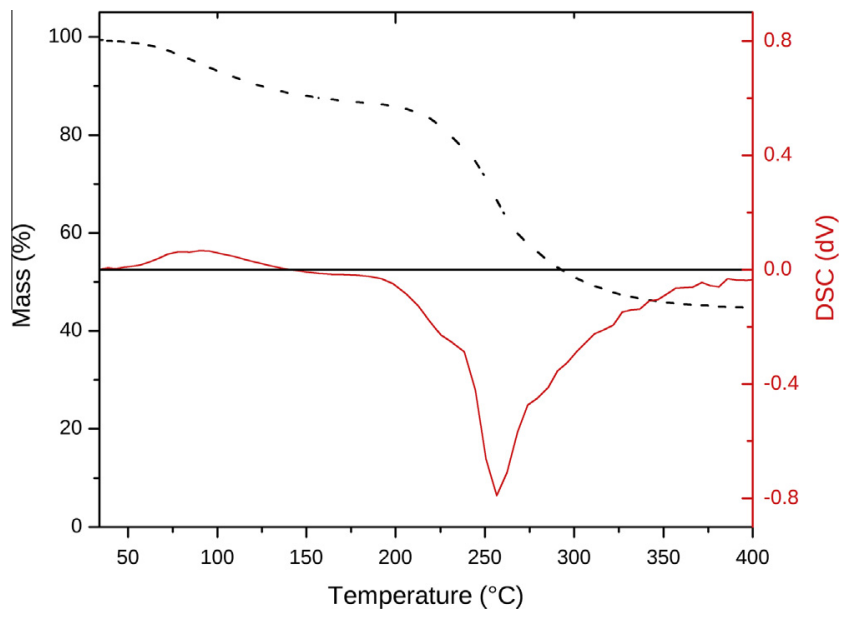

Fig. 1. Thermal analysis of the chemical precursor powder; the DSC (differential scanning calorimetry) is the solid line while TG (thermogravimetry) is the dashed line. The values of the heat flow ( $\mathrm{d} V$ ) can be read in the right axis, the positive peaks $\mathrm{d} V>0$ are referred to endothermic processes, the negative ones $t$ exothermic processes. The analysis was performed under nitrogen atmosphere.

between 100 and $150^{\circ} \mathrm{C}$, this is probably due to humidity. In the same figure one can see a great mass loss $\left(200-300^{\circ} \mathrm{C}\right)$ due to thermal degradation of the chemical precursor, that stabilizes after $300^{\circ} \mathrm{C}$. From the DSC spectra one can see the exothermic peak referred to the decomposition of the precursor at $256{ }^{\circ} \mathrm{C}$. So we decided to perform the thermal treatment at $300^{\circ} \mathrm{C}$ to ensure a complete degradation of the chemical precursor.

The XRD analysis, performed on the powdered residues of the chemical precursor after the TG, has shown a pattern typical of amorphous materials, without any diffraction peaks. This could be due to the low processing temperature $\left(300^{\circ}\right)$ that is not enough to induce the formation of crystals. Further details are provided in Supporting Information (SI).

High uniform CoS thin films have been deposited on FTO substrates following the procedure described in the previous section. In order to obtain information on the morphology of the electrode surface, SEM has been used. The images were collected in a central region and near the border of the electrode. As can be seen from Fig. 2 (a), the film obtained is uniform and does not presents any nano-sized structure, in the same figure one can see a little hole on the surface. Looking at Fig. 2(b) we can see that near the border of the substrate there are some imperfections, due to the processing of the electrodes before SEM analysis. In this region we can see the differences between the amorphous cobalt sulfide film and the FTO substrate. In the same Fig. 2(b) we can also see that the film is homogeneous far from the scratched region. In Fig. 2(c) we can see a magnification of the scratched region near the border of the electrode that clearly shows the morphological differences between the crystalline FTO substrate and the amorphous cobalt sulfide layer. In order to determinate the chemical composition of the layer EDS has been
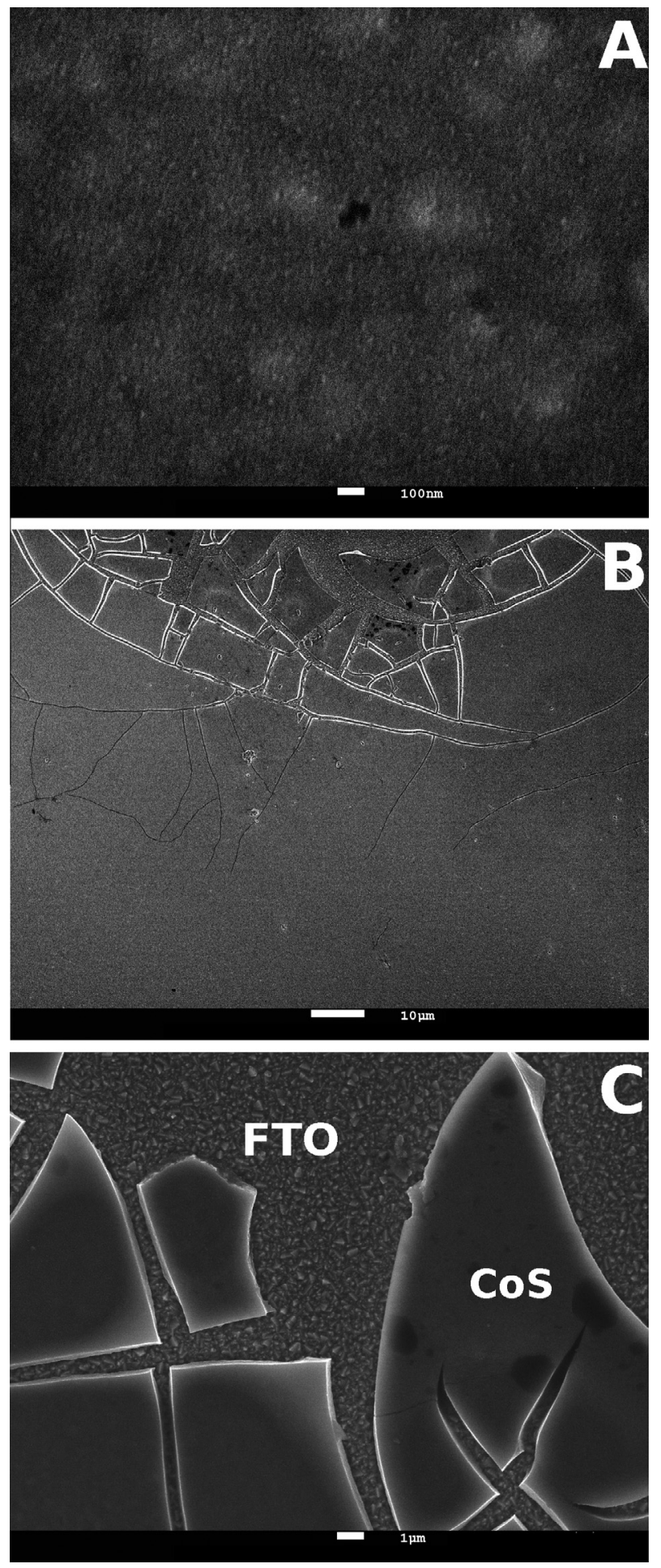

Fig. 2. SEM-FEG images of the central region of the counter electrode (a); at the border near a scratch (b); the same region of (b) with higher magnification (c). In (c) we can see the morphological differences between the crystalline FTO substrate and the amorphous CoS layer.

performed in several regions of the electrode. From the EDS analysis (please see the SM) the atomic ratio between $\mathrm{Co}$ and $\mathrm{S}$ is near 1:1. The EDS spectra have revealed the presence of traces of oxygen in the film, probably due to a partial oxidation of the material during the thermal 
treatment. Another evidence of the 1:1 stoichiometry is that if the films are processed at higher temperature $\left(400{ }^{\circ} \mathrm{C}\right)$, the peaks of the hexagonal $\mathrm{CoS}$ phase starts to appear. For further details please see the SI.

In order to evaluate the performance of the material for DSSC applications, the electrodes have been used both in dummy cells and complete solar cells devices. In the case of the dummy cells, four different electrolytes have been used. Cyclic voltammetry has been performed on the sealed dummy devices and the curves are plotted in Fig. 3. As can be seen all of the redox couples considered in this work $\left(\mathrm{I}^{-} / \mathrm{I}_{3}^{-} ; \mathrm{Fc} / \mathrm{Fc}^{+} ;\left[\mathrm{Co}(\mathrm{bpy})_{3}\right]^{2+/ 3+}\right.$ and $\left.\mathrm{S}^{2-} / \mathrm{S}_{\mathrm{n}}^{2-}\right)$ are reversible on the electrode surfaces. In Fig. 3 we can see the voltammogram of the dummy cell filled with the high stability liquid electrolyte based on the $\mathrm{I}^{-} / \mathrm{I}_{3}^{-}$redox couple, commonly used for DSSCs. The perfect hysteresis of the current/voltage graph shows the complete reversibility of both the reduction and oxidation reaction.

From Fig. 3 we can also calculate the limit current of the HSE in the dummy cell; $11.2 \pm 0.4 \mathrm{~mA} \mathrm{~cm}^{-2}$ for both the anodic and cathodic part of the curve after $200 \mathrm{mV}$. The green line in Fig. 3, represents the voltammogram relative to the cobalt-based liquid electrolyte. As can be seen the $\left[\mathrm{Co}(\text { bpy })_{3}\right]^{2+/ 3+}$ redox couple shows also a complete reversibility. In fact the curve is symmetric and, in the saturation region, the values of the limiting currents are equal in modulus $\left(5.1 \pm 0.8 \mathrm{~mA} \mathrm{~cm}^{-2}\right)$.

The complete reversibility of the redox couple was observed also for the ferrocene/ferrocenium redox couple in the FCE electrolyte, as can be seen in Fig. 3. The limiting in this case was $7.3 \pm 0.5 \mathrm{~mA} \mathrm{~cm}^{-2}$. With the QDSSC polysulfide electrolyte (PSE) the reversibility is also observed with a limiting current of $10.8 \pm 1.3 \mathrm{~mA} \mathrm{~cm}^{-2}$.

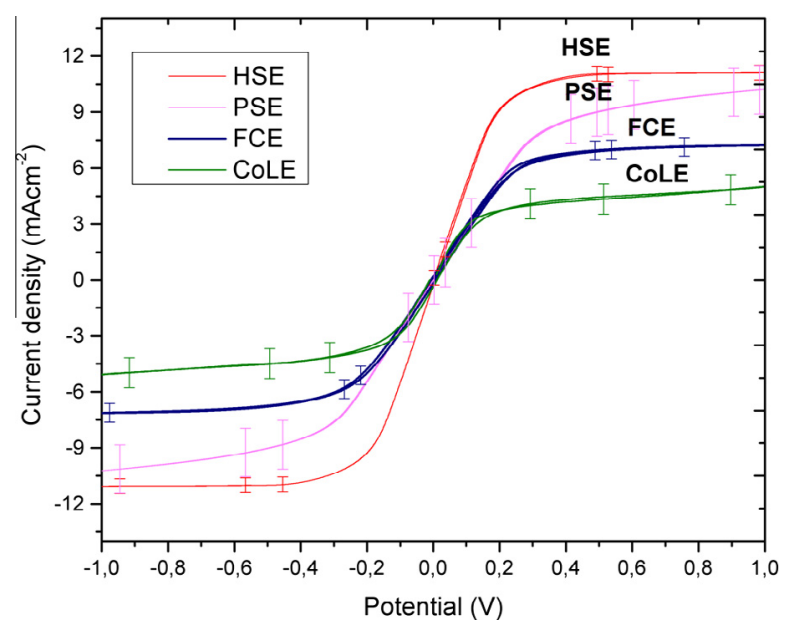

Fig. 3. Typical voltammogram ( 10 cycles, $100 \mathrm{mV} \mathrm{s}^{-1}$ ) of a $0.5 \mathrm{~cm}^{2}$ dummy cell of two cobalt sulfide counter electrodes filled with the iodine/iodide (red line), cobalt polypyridine (green line) and Ferrocene liquid electrolyte (blue line). Polysulfide QDSSC electrolyte (pink line). The respective error bars are plotted on the graphs $(n=3)$. (For interpretation of the references to color in this figure legend, the reader is referred to the web version of this article.)
Impedance spectroscopy has been used to characterize the dummy cells. The spectra have been fitted with the Randles equivalent circuit (Fig. 4).

In order to calculate the charge transfer resistance $\left(R_{\mathrm{ct}}\right)$, the double layer capacitance $\left(C_{\mathrm{dl}}\right)$ and the series resistance $\left(R_{\mathrm{s}}\right)$ of the CEs in each electrolyte. Warburg finite length diffusion element $\left(W_{\mathrm{s}}\right)$ have been used in order to obtain information from the low frequencies impedance associated to the ions diffusion in the electrolyte. The experiments have been performed with three experimental replicates $(n=3)$ and the average values, extracted from the EIS fitting analysis, are reported in Table1.

As can be seen in Table 1 the CoS CEs shows good charge transfer characteristics in all considered electrolytes. For comparison purposes we have included in Table 1 results from a Pt based CE in HSE. As can be seen for the HSE electrolyte the $R_{\mathrm{ct}}$ obtained using the $\mathrm{CoS} \mathrm{CE}$ $\left(1.53 \pm 0.25 \Omega \mathrm{cm}^{2}\right)$ is lower than that obtained with the Pt-FTO $\left(2.32 \pm 0.15 \Omega \mathrm{cm}^{2}\right)$. The value of $R_{\mathrm{ct}}$ obtained with the PSE electrolyte was $\left(5.30 \pm 0.44 \Omega \mathrm{cm}^{2}\right)$ showing a performance similar to that of the $\mathrm{CoS}_{2}$ CEs for QDSSC proposed by Rao et al. (2015).

The CoS CEs were used in DSSC devices using D5 and N719 dyes with HSE. The Pt-FTO has been used as reference using the same cell configuration. The cells were characterized by current-voltage curves to calculate the photovoltaic parameters (PV). The typical IV curves for the $0.25 \mathrm{~cm}^{2}$ SP photoanodes, sensitized with D5 dye, are reported in Fig. 5 and the photovoltaic parameters are resumed in Table 2.

The cells were sealed using two different counter electrodes, Pt-FTO (-o-) and CoS (- $\mathbf{\Delta -}$ ). From the two curves

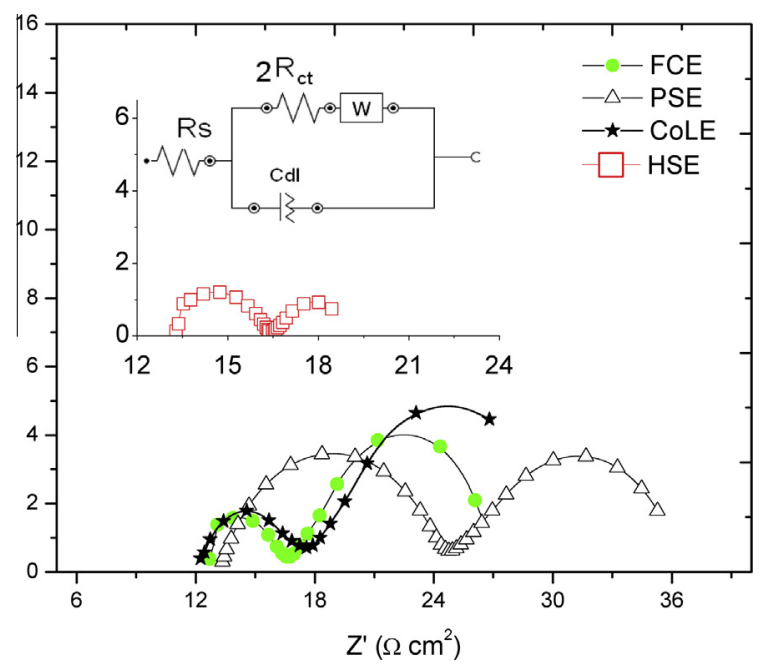

Fig. 4. Nyquist plots of the impedance measurements performed on dummy cells devices filled with the four different electrolytes (HSE, FCE, CoLE and PSE). In the insert a representation of the equivalent circuit, used to perform the fitting of the experimental data, is shown. In the circuit we can see the series resistance $R_{\mathrm{s}}$, the charge transfer resistance $R_{\mathrm{ct}}$, the Warburg diffusive element and the constant phase capacitive element Cdl. 
Table 1

Fitted parameters \pm standard deviation $(n=3)$ of dummy cells filled with the different electrolytes. The measurements were performed at 0 V offset.

\begin{tabular}{|c|c|c|c|c|c|c|c|c|}
\hline Electrolyte & $\mathrm{CE}$ & $R_{\mathrm{s}}\left(\Omega \mathrm{cm}^{2}\right)$ & $R_{\mathrm{ct}}\left(\Omega \mathrm{cm}^{2}\right)$ & $C_{\mathrm{dl}}\left(\mu \mathrm{F} \mathrm{cm}^{-2}\right)$ & $n$ & $W_{\mathrm{s}}-R$ & $W_{\mathrm{s}}-T$ & $W_{\mathrm{s}}-P$ \\
\hline HSE & $\mathrm{CoS}$ & $13.34 \pm 1.50$ & $1.53 \pm 0.25$ & $12.0 \pm 0.1$ & $0.81 \pm 0.10$ & $2.31 \pm 0.50$ & $1.32 \pm 0.15$ & $0.38 \pm 0.10$ \\
\hline HSE & $\mathrm{Pt}$ & $12.33 \pm 1.34$ & $2.32 \pm 0.15$ & $40.9 \pm 3.5$ & $0.96 \pm 0.12$ & $2.54 \pm 0.43$ & $1.16 \pm 0.21$ & $0.51 \pm 0.09$ \\
\hline CoLE & $\mathrm{CoS}$ & $12.25 \pm 1.07$ & $2.40 \pm 0.20$ & $18.0 \pm 2.2$ & $0.80 \pm 0.15$ & $13.00 \pm 1.35$ & $2.81 \pm 0.20$ & $0.44 \pm 0.10$ \\
\hline FCE & $\mathrm{CoS}$ & $12.70 \pm 1.20$ & $2.23 \pm 0.25$ & $4.1 \pm 0.6$ & $0.79 \pm 0.19$ & $10.46 \pm 2.17$ & $0.83 \pm 0.12$ & $0.38 \pm 0.15$ \\
\hline PSE & $\mathrm{CoS}$ & $13.34 \pm 2.00$ & $5.30 \pm 0.44$ & $1.3 \pm 0.6$ & $0.78 \pm 0.11$ & $6.92 \pm 2.10$ & $1.25 \pm 0.55$ & $0.50 \pm 0.21$ \\
\hline
\end{tabular}

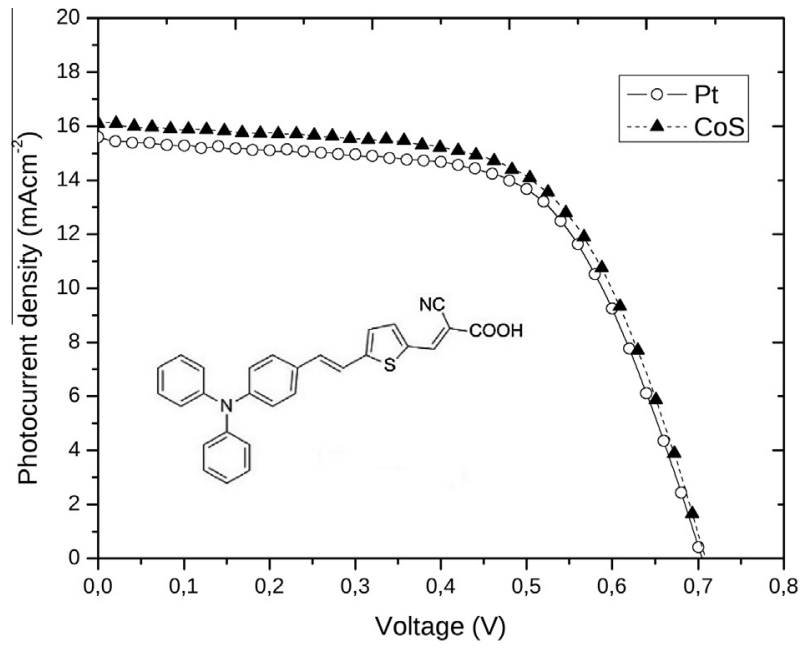

Fig. 5. Typical IV curves of $0.25 \mathrm{~cm}^{2}$ DSSCs sensitized with the D5 dye, whose structure is shown in the figure. The IV characterization was performed at AM 1.5 simulated sun light. The standard deviation associated to the current measurements are reported in Table 2.

it is possible to see that the two DSSCs achieve similar values of $V_{\text {oc }}$ and $J_{\text {sc }}$ showing a similar performance.

From Table 2 it can be seen that the CoS CEs showed a performance very similar to that of the Pt electrode in all configurations used. Using the D5 dye the photo-current density obtained in the SP CoS cell was $16.4 \mathrm{~mA} \mathrm{~cm}^{2}$ very close to that obtained using the Pt-FTO in the same cell configuration $\left(15.7 \mathrm{~mA} \mathrm{~cm}^{2}\right)$. Due to the larger area and also the different deposition system, the devices fabricated using the DB photo-anodes shown PV performance lower than that of the SP devices with both D5 and N719 dyes and both Pt-FTO and CoS CEs. As can be seen in Table 2, using the D5 dye we obtained an improvement in the FF of the devices however both the photo-current and the efficiencies was lower than those achieved with N719. Further details on DSSCs devices and stability are provided in the SI.

\section{Discussion}

As described in the previous section, the synthesis and preparation methods are simple. The precursor ink can be easily prepared using standard laboratory glassware, cheap reagents and no toxic or dangerous solvents. The one step synthesis of the CoTGA complex is performed at $\mathrm{pH} 7$, after the neutralization of the thioglycolic acid solution with diluted ammonium hydroxide. Cobalt chloride $\mathrm{CoCl}_{2}$ has been used as the source of $\mathrm{Co}^{2+}$ ions. For this reason it is important that the neutralization of TGA is performed using ammonium hydroxide instead of $\mathrm{NaOH}$. The use of $\mathrm{NH}_{3} \mathrm{OH}$ ensures the complete removal of $\mathrm{Cl}^{-}$ions traces after thermal treatment. In fact any possible traces of chloride are removed as $\mathrm{NH}_{4} \mathrm{Cl}$, since it evaporates at the annealing temperatures used. The ink is dropped on the substrate and, after the evaporation of the solvent (water), a thin uniform film is obtained without the formation of aggregates nor crystals. After a thermal treatment $\left(300{ }^{\circ} \mathrm{C}, 30 \mathrm{~min}\right)$ the precursor is completely converted in amorphous CoS. The synthetic pathway is resumed by the following chemical reactions:

$$
\begin{aligned}
& \mathrm{HSCH}_{2} \mathrm{CO}_{2} \mathrm{H}+\mathrm{NH}_{4} \mathrm{OH} \rightarrow \mathrm{HSCH}_{2} \mathrm{CO}_{2} \mathrm{NH}_{4}+\mathrm{H}_{2} \mathrm{O} \\
& \mathrm{HSCH}_{2} \mathrm{CO}_{2} \mathrm{NH}_{4}+\mathrm{CoCl}_{2}+\mathrm{NH}_{4} \mathrm{OH} \\
& \rightarrow \mathrm{CoSCH}_{2} \mathrm{CO}_{2}+2 \mathrm{NH}_{4} \mathrm{Cl}+\mathrm{H}_{2} \mathrm{O}
\end{aligned}
$$

In reaction (1) the first step of the preparation of the chemical precursor is described as in the materials and methods section. In this acid/base reaction the ammonium salt of the TGA is formed. The addition of the $\mathrm{CoCl}_{2}$ solution led to the formation of the water soluble complex

Table 2

Photovoltaic parameters of DSSCs with N719 and D5 dyes and different CE ( \pm standard deviation $n=3$ ). The small area $0.25 \mathrm{~cm}^{2}$ photoanodes (bold values) were fabricated through screen-printing (SP) while the larger photoanodes were fabricated by doctor blade process (DB). All measurements were performed under simulated sun light (AM 1.5).

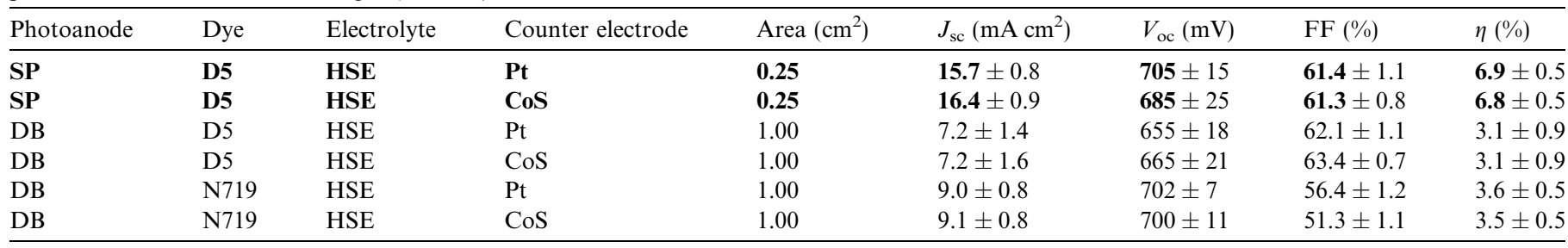


CoTGA (Eq. (2)) with the deprotonation of the -SH moiety of the thioglycolic acid. The loss of the thiolic proton is confirmed by FTIR spectra that can be seen in Fig. 6 .

As can be seen in Fig. 6, the signal of $\mathrm{S}-\mathrm{H}$ stretching $\left(\approx 2550 \mathrm{~cm}^{-1}\right)$ visible in TGA, does not appear in the complex. The signal of the carbonyl group, at $1732 \mathrm{~cm}^{-1}$ for the TGA, is shifted to $1585 \mathrm{~cm}^{-1}$ in the CoTGA complex. This shift is due to the deprotonation of the acid $-\mathrm{OH}$ group and its participation as a ligand in the formation of the complex with the $\mathrm{Co}^{2+}$ ion. It is important to remember that the reaction (2) of ammonium thioglycolate (perm salt) with transition metals ions has been widely used for the colorimetric determination of toxic metals in water (Swank and Mellon, 1938). In fact the complexes formed by the dianion $-\mathrm{SCH}_{2} \mathrm{CO}_{2}^{-}$are strongly colored. Another important remark is the very low toxicity of ammonium thioglycolate, that is commonly used in commercial hair permanent products. As the complex is highly soluble in water and completely insoluble in alcohols, the precipitation has been performed adding small quantities of absolute ethanol in the reaction vessel. Ethanol was used also for the washing step, in order to remove the unreacted reagents from the powder. From the thermogravimetric graph of Fig. 1 it can be seen a first mass loss after $100^{\circ} \mathrm{C}$ due to the removal of absorbed water in the powder, in the DSC graph one can see an endothermic peak in the same region. The presence of water was also confirmed by the characteristic signal in the FTIR spectrum. Around $256^{\circ} \mathrm{C}$ a great mass loss due to the degradation of the complex can be seen due to the cleavage of the carbon-sulfur bond $(\approx 62 \mathrm{kcal} / \mathrm{mol})$. The exothermic peak referred to the degradation reaction of the metal complex can be seen in the DSC graph. After the temperature ramp $\left(30-400{ }^{\circ} \mathrm{C}\right)$, TG shows a mass loss of $39 \%$. Considering the molecular weight of $\mathrm{CoSCH}_{2} \mathrm{CO}_{2}\left(149.02 \mathrm{~g} \mathrm{~mol}^{-1}\right)$ the molecular weight of the residue, that remains after the degradation is $90.88 \mathrm{~g} \mathrm{~mol}^{-1}$; a value close to the molecular weight of $\mathrm{CoS}\left(90.99 \mathrm{gmol}^{-1}\right)$. The stoichiometry of the compound

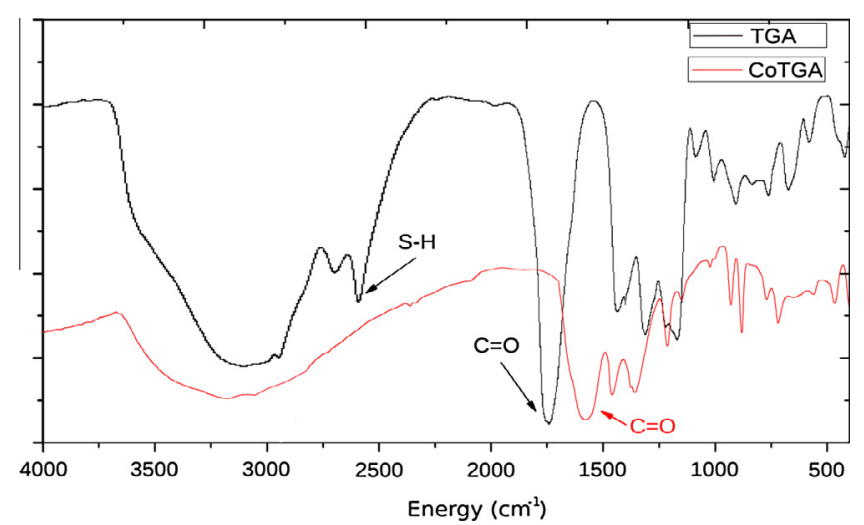

Fig. 6. FTIR spectra of thioglycolic acid (black line) and the CoTGA complex (red line). The typical signals of the carbonyl and thiol groups are visible in the spectra. (For interpretation of the references to color in this figure legend, the reader is referred to the web version of this article.) has been confirmed by EDS and also XRD analysis on films, 1:1 Co:S ratio.

The precursor ink consists of a $1 \mathrm{mg} / \mathrm{mL}$ solution of $\mathrm{CoSCH}_{2} \mathrm{CO}_{2}$ complex in deionized water. In order to make the evaporation faster, the ink can be prepared using ethanol:water 40:60 (v:v). However all of the experiments reported in this work have been performed using just deionized water as solvent. Considering the results of the thermal analysis we decided to perform the thermal treatment at $300{ }^{\circ} \mathrm{C}$ in nitrogen for $30 \mathrm{~min}$. In these conditions the precursor is completely converted in a uniform layer of amorphous cobalt sulfide. The amorphous nature of the $\mathrm{CoS}$ produced by this process was confirmed by both XRD spectroscopy and DSC analysis. In fact as can be seen in the SI, at $300{ }^{\circ} \mathrm{C}$ no peaks are visible in the XRD spectrum. Another experimental evidence, that confirms the amorphous nature of the $\mathrm{CoS}$ film is the absence of endothermic peaks after the exothermic degradation peak. Generally in DSC of inorganic compounds endothermic peaks correspond either to crystallization/recrystallization processes (Handbook of Thermal Analysis and Calorimetry: Applications to inorganic and miscellaneous materials, 2003). As shown in the SEM images (Fig. 3a-c) it is possible to see the morphology of the $\mathrm{CoS}$ layer, completely different from the crystalline FTO. The values of $R_{\mathrm{s}}$ calculated by fitting the EIS data are consistent in all of the samples. Notice that these values depend just on the electric contact between the active $\operatorname{CoS}$ layer, the FTO substrate and the EIS measurement system and are independent of the electrolyte used. However in order to obtain uniform values of $R_{\mathrm{s}}$, the part of the electrode used for the contact have to be free of CoS, since the presence of a CoS film in the contact region could change the values of resistance in the contact point. So we suggest to remove the precursor from the contact area after the deposition by partially dipping the electrode in water. In this way, after the thermal treatment this part will be free of any $\mathrm{CoS}$ residue and one can contact the electrode directly to FTO. CoS films deposited on FTO glass have shown a good electrocatalytic activity with the $\mathrm{I}^{-} / \mathrm{I}_{3}^{-}$redox couple in HSE for DSSCs. In fact the counter electrodes based on amorphous CoS showed lower $R_{c t}$ values in comparison to that obtained with Pt-FTO. As we discussed in our previous paper on crystalline CoS CEs, obtained with a similar process, the higher efficiency of the CoS can be correlated with its faster charge recombination (Congiu et al., 2015) in comparison with Pt-FTO. Also in the case of the amorphous CoS CE a faster charge recombination can be seen. In fact if we consider the relaxation time of the system (time constant) (Barsoukov and Macdonald, 2005; Macdonald, 1992) $\tau$, defined by:

$\tau=R_{\mathrm{ct}} C_{\mathrm{dl}}$

The terms $R_{\mathrm{ct}}$ and $C_{\mathrm{dl}}$ are calculated directly from the fitting of the EIS spectra using the Randles circuit. The value of the time constant for the $\mathrm{CoS} C \mathrm{CE}$ is 18.3 $\pm 0.2 \mu$ s while, for the Pt-FTO is $93.0 \pm 2.1 \mu \mathrm{s}$. As can be 
seen from the Table 1, the CoS has shown values of both $C_{\mathrm{dl}}$ and $R_{\mathrm{ct}}$ lower than those of Pt-FTO. In what concerns the other two alternative electrolytes for DSSC, $\mathrm{Fc} / \mathrm{Fc}^{+}$ and $\left[\mathrm{Co}(\mathrm{bpy})_{3}\right]^{2+/ 3+}$ an interesting result is the time constants associated to the charge transfer process of $\mathrm{Fc} / \mathrm{Fc}^{+}$ and $\left[\mathrm{Co}(\mathrm{bpy})_{3}\right]^{2+/ 3+}$, respectively $9.1 \pm 0.4$ and 43.2 $\pm 1.2 \mu$ s. Looking at Table 1 , we can see that the value of $R_{\mathrm{ct}}$ associated to the charge transfer process at the $\mathrm{CoS}$ electrode surface of $\mathrm{Fc} / \mathrm{Fc}^{+}$it is very close to that of $\left[\mathrm{Co}(\mathrm{bpy})_{3}\right]^{2+/ 3+}$. So the only factor that makes the time constant of the $\left[\mathrm{Co}(\mathrm{bpy})_{3}\right]^{2+/ 3+}$ higher than that of the ferrocene is its higher capacitance. According to the classic Gouy-Chapman and also Grahame models, when an electrode is immersed in an electrolyte solution an electric double layer is created. The double layer is composed of a charged surface (the electrode) and a mono-molecular layer of absorbed counter ions, with the charge opposite to that of the electrode surface. The co-ions, with the same charge generated on the surface, are depleted from the electrode/ electrolyte region. The higher the charge of the absorbed ion the higher is the charge (with the opposite sign) induced on the electrode surface (Scholz, 2009; Velikonja et al., 2014). So the higher capacitance observed with CoLE electrolyte can be due to the higher charge of the ions composing the redox couple, in fact the polypyridine complexes of cobalt are bivalent and trivalent ions while the $\mathrm{Fc}^{+}$ion has a single positive charge and its reduced form it is a neutral molecule $\mathrm{Fc}^{0}$.

Among the iodine-free electrolytes, the best results have been obtained with ferrocene electrolyte with a $R_{\mathrm{ct}}$ of 2.23 $\pm 0.25 \Omega \mathrm{cm}^{2}$ and a limit current of $7.3 \pm 0.5 \mathrm{~mA} \mathrm{~cm}^{-2}$. In both electrolytes, the value of the limiting current is lower than the currents obtained using HSE. It is important to remember that the HSE used in this work is a commercial product, optimized with high efficient additives, while the FCE electrolyte does not contain any additive and thus could be further optimized using additives. In fact from the impedance spectrum (Fig.4) we can see that the higher part of the whole resistance of the dummy cell, is due to the diffusion resistance.

$\mathrm{Fc} \rightarrow \mathrm{Fc}^{+}+1 \mathrm{e}^{-} \quad\left(\mathrm{E}^{0}=0.64 \mathrm{~V}\right.$ vs. SHE $)$

A similar behavior was observed in the dummy cells filled with the cobalt-based electrolyte. In fact with the CoLE we can see that a great part of the resistance of the whole device is due to ions diffusion between the two electrodes. The charge transfer resistance associated to the oxidation/reduction of the $\left[\mathrm{Co}(\mathrm{bpy})_{3}\right]^{2+/ 3+}$ redox shutthe at the electrode surface is $2.40 \pm 0.19 \Omega \mathrm{cm}^{2}$. The charge transfer resistances observed with both FCE (2.23 $\left.\pm 0.25 \Omega \mathrm{cm}^{2}\right)$ and CoLE $\left(2.40 \pm 0.19 \Omega \mathrm{cm}^{2}\right)$ were higher than the resistance observed with the $\mathrm{I}^{-} / \mathrm{I}_{3}^{-} \quad(1.53$ $\pm 0.25 \Omega \mathrm{cm}^{2}$ ). To explain these differences we have to consider the diffusive behavior of the different molecular ions dissolved in a liquid electrolyte. It is important to remember that the diffusion coefficients of a redox couple can be calculated from the Stokes Einstein equation (Eq. (5)).
$D=\frac{k T}{6 \pi \eta a}$

In Eq. (5) $k$ is the Boltzmann constant, $T$ the temperature, $\eta$ the viscosity and $a$ the effective hydrodynamic radius (approximating the ion as a sphere). As can be seen in the EIS spectra (Fig.4) of the dummy cells filled with FCE and CoLE, the diffusion resistance (lower frequencies signals) are higher than that associated to the diffusion of the triiodide ion. The higher is the diffusion resistance the lower is the diffusion coefficient (Liberatore et al., 2009). The fitted values for the Warburg finite length diffusion $\left(W_{\mathrm{s}}\right)$ are reported in Table 1. As can be seen, the real part of the impedance of the diffusion $\left(W_{\mathrm{s}}-R\right)$ associated to CoLE and FCE are significantly higher than those for HSE. Limitations in the performance of CoLE electrolytes, related to the low mass diffusion coefficients have been reported so far in the literature (Klahr and Hamann, 2009), as well as the strategies to its improvements (Kim et al., 2011; Liberatore et al., 2009; Petrocco et al., 2010). Among the factors that reduce the diffusion coefficient looking at the Eq. (5), is the effective hydrodynamic radius of the ion. This value depends on several factors, such as the solubility, the interactions between solvent and solute and finally the effective dimension of the ion. Note that both the $\mathrm{Fc}^{+}$and the $\left[\mathrm{Co}(\mathrm{bpy})_{3}\right]^{2+/ 3+}$ are considerably bigger than the $\mathrm{I}_{3}^{-}$ion. However the values of the $R_{\mathrm{ct}}$ obtained with FCE and CoLE are comparable to that of the commonly used Pt-FTO counter electrode with the $\mathrm{I}^{-} / \mathrm{I}_{3}^{-}$electrolyte. So the only factor that limits the current is the low mass transport coefficient, characteristic of both $\mathrm{Fc}$ and $\left[\mathrm{Co}(\mathrm{bpy})_{3}\right]^{2+/ 3+}$ redox shuttles. The limiting current can be further improved using a thinner spacer between the electrodes, using less viscous solvents (Latini et al., 2014) and also increasing the porosity of the electrode surface (Kim et al., 2011; Petrocco et al., 2010). The limiting currents obtained with FCE and CoLE electrolytes were respectively $7.3 \pm 0.5$ and $5.1 \pm 0.8 \mathrm{~mA} \mathrm{~cm} \mathrm{~cm}^{2}$. These values are low when compared with the photocurrent densities observed in high performance DSSC devices, however the combination of amorphous $\mathrm{CoS}$ counter electrodes (this work) and a CoLE or a FCE electrolytes could be interesting for indoor DSSCs where lower photo-current densities are expected. Furthermore it is important to remark that both FCE and CoLE are less reactive and corrosive than the commonly used $\mathrm{I}^{-} / \mathrm{I}_{3}^{-}$redox couple and thus could extend the lifetime of the devices.

\section{Conclusions}

In this work a cheap, easy, fast and reliable single precursor method was developed for the deposition of high catalytic CoS layers on FTO substrates. We demonstrated that $\mathrm{CoS}$ can be prepared with a printing-compatible technique, based on cheap and abundant materials. These electrodes can operate with different redox couples in the liquid electrolytes used in solar cells devices. The precursor used 
in this work $\mathrm{CoSCH}_{2} \mathrm{CO}_{2}$, a complex of $\mathrm{Co}$ (II) and thioglycolic acid, is water soluble. The water based solution of the chemical precursor was used as an Ink for the drop casting deposition over FTO. The precursor was then completely converted in CoS by means of a thermal treatment. The possibility of using water as the solvent, makes this method attractive for large-area and industrial application. The electrodes produced through this method have shown an excellent electrocatalytic activity for the oxidation/reduction of $\mathrm{I}^{-} / \mathrm{I}_{3}^{-}$redox couple, commonly used in DSSC devices. The efficiency of these $\mathrm{CoS}$ counter electrodes were evaluated with other redox shuttles for DSSC such as the $\mathrm{Co}(\mathrm{II}) / \mathrm{Co}$ (III) bipyridine complex and ferrocene/ferrocenium, also showing a good electrocatalytic activity with complete electrochemical reversibility. The $\mathrm{CoS}$ electrodes were also shown to be useful in QDSSC, in fact the experiments performed using polysulfide electrolyte have shown a perfect reversibility and good charge transfer kinetics. The CoS electrodes were used in DSSCs sensitized with the D5 organic dye with good PV performance comparable to the commonly used Pt-FTO electrodes. Our CoS counter electrodes could be considered for a future study involving other kind of electrolytes such as hole transporting materials and gel electrolytes, in order to evaluate the application of $\mathrm{CoS}$ to other kind of solar cells devices such as organic solar cells.

\section{Acknowledgements}

This work was supported by FAPESP (Fundação de Amparo à Pesquisa do Estado de São Paulo, Proc: 2013/07396-7, 2013/25028-5 and 2008/57872-1) and CAPES (Coordenação de Aperfeiçoamento de Pessoal de Nível Superior), CAPES 024/2012 Pro-equipamentos. We want to thank the university of Rome Tor Vergata and the university of Rome "La Sapienza" for having allowed the use of its facilities. Graphical abstract by Fernanda Montanher Matheus, Designer.

\section{Appendix A. Supplementary material}

Supplementary data associated with this article can be found, in the online version, at http://dx.doi.org/10.1016/ j.solener.2015.08.032.

\section{References}

AbdulAlmohsin, S., Mohammed, M., Li, Z., Thomas, M.A., Wu, K.Y., Cui, J.B., 2012. Multi-walled carbon nanotubes as a new counter electrode for dye-sensitized solar cells. J. Nanosci. Nanotechnol. 12, 2374-2379.

Ahmad, I., McCarthy, J.E., Bari, M., Gun'ko, Y.K., 2014. Carbon nanomaterial based counter electrodes for dye sensitized solar cells. Sol. Energy 102, 152-161. http://dx.doi.org/10.1016/ j.solener.2014.01.012.

Ahn, J.Y., Kim, J.H., Kim, J.M., Lee, D., Kim, S.H., 2014. Multiwalled carbon nanotube thin films prepared by aerosol deposition process for use as highly efficient Pt-free counter electrodes of dye-sensitized solar cells. Sol. Energy 107, 660-667. http://dx.doi.org/10.1016/j.solener. 2014.06.015.

Anwar, H., George, A.E., Hill, I.G., 2013. Vertically-aligned carbon nanotube counter electrodes for dye-sensitized solar cells. Sol. Energy 88, 129-136. http://dx.doi.org/10.1016/j.solener.2012.11.013.

Barsoukov, E., Macdonald, J.R., 2005. Impedance Spectroscopy: Theory, Experiment, and Applications. John Wiley \& Sons.

Boschloo, G., Hagfeldt, A., 2009. Characteristics of the iodide/triiodide redox mediator in dye-sensitized solar cells. Acc. Chem. Res. 42, 18191826. http://dx.doi.org/10.1021/ar900138m.

Congiu, M., Albano, L.G.S., Decker, F., Graeff, C.F.O., 2015. Single precursor route to efficient cobalt sulphide counter electrodes for dye sensitized solar cells. Electrochim. Acta 151, 517-524. http://dx.doi. org/10.1016/j.electacta.2014.11.001.

Daeneke, T., Kwon, T.-H., Holmes, A.B., Duffy, N.W., Bach, U., Spiccia, L., 2011. High-efficiency dye-sensitized solar cells with ferrocene-based electrolytes. Nat. Chem. 3, 211-215. http://dx.doi.org/10.1038/ nchem.966.

Faber, M.S., Park, K., Cabán-Acevedo, M., Santra, P.K., Jin, S., 2013. Earth-abundant cobalt pyrite $(\mathrm{CoS} 2)$ thin film on glass as a robust, high-performance counter electrode for quantum dot-sensitized solar cells. J. Phys. Chem. Lett. 4, 1843-1849. http://dx.doi.org/10.1021/ jz400642e.

Feldt, S.M., Gibson, E.A., Gabrielsson, E., Sun, L., Boschloo, G., Hagfeldt, A., 2010. Design of organic dyes and cobalt polypyridine redox mediators for high-efficiency dye-sensitized solar cells. J. Am. Chem. Soc. 132, 16714-16724. http://dx.doi.org/10.1021/ja1088869.

Fu, N., Xiao, X., Zhou, X., Zhang, J., Lin, Y., 2012. Electrodeposition of platinum on plastic substrates as counter electrodes for flexible dyesensitized solar cells. J. Phys. Chem. C 116, 2850-2857. http://dx.doi. org/10.1021/jp206676s.

Hamann, T.W., 2012. The end of iodide? cobalt complex redox shuttles in DSSCs. Dalton Trans. 41, 3111-3115. http://dx.doi.org/10.1039/ c2dt12362b.

Handbook of Thermal Analysis and Calorimetry: Applications to Inorganic and Miscellaneous Materials, 2003, Elsevier.

Jun, H.K., Careem, M.A., Arof, A.K., 2013. A suitable polysulfide electrolyte for CdSe quantum dot-sensitized solar cells. Int. J. Photoenergy.

Ke, W., Fang, G., Lei, H., Qin, P., Tao, H., Zeng, W., Wang, J., Zhao, X., 2014. An efficient and transparent copper sulfide nanosheet film counter electrode for bifacial quantum dot-sensitized solar cells. J. Power Sources 248, 809-815. http://dx.doi.org/10.1016/j. jpowsour.2013.10.028.

Khelashvili, G., Behrens, S., Weidenthaler, C., Vetter, C., Hinsch, A., Kern, R., Skupien, K., Dinjus, E., Bönnemann, H., 2006. Catalytic platinum layers for dye solar cells: a comparative study. Thin Solid Films 511, 342-348.

Kim, H.-S., Ko, S.-B., Jang, I.-H., Park, N.-G., 2011. Improvement of mass transport of the $\left[\mathrm{Co}(\mathrm{bpy})_{3}\right](\mathrm{II} / \mathrm{III})$ redox couple by controlling nanostructure of $\mathrm{TiO}_{2}$ films in dye-sensitized solar cells. Chem. Commun. (Camb) 47, 12637-12639. http://dx.doi.org/10.1039/ clcc14991a.

Klahr, B.M., Hamann, T.W., 2009. Performance enhancement and limitations of cobalt bipyridyl redox shuttles in dye-sensitized solar cells. J. Phys. Chem. C 113, 14040-14045. http://dx.doi.org/10.1021/ jp903431s.

Lan, J.-L., Wang, Y.-Y., Wan, C.-C., Wei, T.-C., Feng, H.-P., Peng, C., Cheng, H.-P., Chang, Y.-H., Hsu, W.-C., 2010. The simple and easy way to manufacture counter electrode for dye-sensitized solar cells. Curr. Appl. Phys. 10, S168-S171. http://dx.doi.org/10.1016/ j.cap.2009.11.064.

Latini, A., Aldibaja, F.K., Cavallo, C., Gozzi, D., 2014. Benzonitrile based electrolytes for best operation of dye sensitized solar cells. J. Power Sources 269, 308-316. http://dx.doi.org/10.1016/j. jpowsour.2014.06.154.

Lee, C.-P., Chen, P.-Y., Vittal, R., Ho, K.-C., 2010. Iodine-free high efficient quasi solid-state dye-sensitized solar cell containing ionic 
liquid and polyaniline-loaded carbon black. J. Mater. Chem. 20, 2356. http://dx.doi.org/10.1039/b922350a.

Liberatore, M., Decker, F., Burtone, L., Zardetto, V., Brown, T.M., Reale, A., Di Carlo, A., 2009. Using EIS for diagnosis of dyesensitized solar cells performance. J. Appl. Electrochem. 39, 22912295. http://dx.doi.org/10.1007/s10800-009-9806-5.

Lin, J.-Y., Liao, J.-H., Wei, T.-C., 2011. Honeycomb-like CoS counter electrodes for transparent dye-sensitized solar cells. Electrochem. Solid-State Lett. 14, D41-D44.

Macdonald, J.R., 1992. Impedance spectroscopy. Ann. Biomed. Eng. 20, 289-305. http://dx.doi.org/10.1007/BF02368532.

Mathew, S., Yella, A., Gao, P., Humphry-Baker, R.E.C.F., AshariAstani, N., Tavernelli, I., Rothlisberger, U., Khaja, N., Grätzel, M., 2014. Dye-sensitized solar cells with $13 \%$ efficiency achieved through the molecular engineering of porphyrin sensitizers. Nat. Chem. 6, 242247.

Meng, K., Surolia, P.K., Byrne, O., Thampi, K.R., 2014. Efficient CdS quantum dot sensitized solar cells made using novel $\mathrm{Cu} 2 \mathrm{~S}$ counter electrode. J. Power Sources 248, 218-223. http://dx.doi.org/10.1016/j. jpowsour.2013.09.004.

Mgabi, L.P., Dladla, B.S., Malik, M.A., Garje, S.S., Akhtar, J., Revaprasadu, N., 2014. Deposition of cobalt and nickel sulfide thin films from thio- and alkylthio-urea complexes as precursors via the aerosol assisted chemical vapour deposition technique. Thin Solid Films 564, 51-57. http://dx.doi.org/10.1016/j.tsf.2014.04.086.

O’regan, B., Grätzel, M., 1991. A low-cost, high-efficiency solar cell based on dye-sensitized. Nature 353, 737-740.

Petrocco, A., Liberatore, M., Di Carlo, A., Reale, A., Brown, T.M., Decker, F., 2010. Thermal activation of mass transport and charge transfer at $\mathrm{Pt}$ in the $\mathrm{I}(3)(-) / \mathrm{I}(-)$ electrolyte of a dye-sensitized solar cell. Phys. Chem. Chem. Phys. 12, 10786-10792. http://dx.doi.org/ 10.1039/c002840a.

Rao, S.S., Punnosse, D., Kim, S.-K., Kim, H.-J., 2015. Low-cost solution processed nano millet like structure $\mathrm{CoS} 2$ film superior to $\mathrm{pt}$ as counter electrode for quantum dot sensitized solar cells. Electron. Mater. Lett. 11, 485-493. http://dx.doi.org/10.1007/s13391-014-4158-7.

Scholz, F., 2009. Electroanalytical Methods: Guide to Experiments and Applications. Springer Science \& Business Media.
Sönmezoğlu, S., Akyürek, C., Akin, S., 2012. High-efficiency dyesensitized solar cells using ferrocene-based electrolytes and natural photosensitizers. J. Phys. D. Appl. Phys. 45, 425101. http://dx.doi.org/ 10.1088/0022-3727/45/42/425101.

Swank, H.W., Mellon, M.G., 1938. The determination of iron with mercaptoacetic acid. Ind. Eng. Chem. Anal. Ed. 10, 7-9.

Velikonja, A., Gongadze, E., Kralj-Iglič, V., Iglič, A., 2014. Charge dependent capacitance of stern layer and capacitance of electrode/electrolyte interface. Int. J. Electrochem. Sci. 9, 5885-5894.

Wang, H., Hu, Y.H., 2012. Graphene as a counter electrode material for dye-sensitized solar cells. Energy Environ. Sci. 5, 8182. http://dx.doi. org/10.1039/c2ee21905k.

Wang, M., Anghel, A.M., Marsan, B., Cevey Ha, N.-L., Pootrakulchote, N., Zakeeruddin, S.M., Grätzel, M., 2009. CoS supersedes Pt as efficient electrocatalyst for triiodide reduction in dye-sensitized solar cells. J. Am. Chem. Soc. 131, 15976-15977.

Yanagida, S., Yu, Y., Manseki, K., 2009. Iodine/iodide-free dye-sensitized solar cells. Acc. Chem. Res. 42, 1827-1838. http://dx.doi.org/10.1021/ ar900069p.

Yang, J., Bao, C., Zhu, K., Yu, T., Li, F., Liu, J., Li, Z., Zou, Z., 2014 High catalytic activity and stability of nickel sulfide and cobalt sulfide hierarchical nanospheres on the counter electrodes for dye-sensitized solar cells. Chem. Commun.

Yella, A., Lee, H.-W., Tsao, H.N., Yi, C., Chandiran, A.K., Nazeeruddin, M.K., Diau, E.W.-G., Yeh, C.-Y., Zakeeruddin, S.M., Grätzel, M., 2011. Porphyrin-sensitized solar cells with cobalt (II/III)-based redox electrolyte exceed 12 percent efficiency. Science 334, 629-634. http:// dx.doi.org/10.1126/science.1209688.

Yun, S., Hagfeldt, A., Ma, T., 2014. Pt-free counter electrode for dyesensitized solar cells with high efficiency. Adv. Mater., doi:101002/ adma.201402056.

Zotti, G., Schiavon, G., Zecchin, S., Favretto, D., 1998. Dioxygendecomposition of ferrocenium molecules in acetonitrile: the nature of the electrode-fouling films during ferrocene electrochemistry. J. Electroanal. Chem. 456, 217-221. http://dx.doi.org/10.1016/S0022-0728 (98)00279-4. 